\title{
Habitat availability drives the distribution-abundance relationship in phytophagous true bugs in managed grasslands
}

\author{
Nicolas Friess, ${ }^{1,4}$ Martin M. Gossner, ${ }^{2,3}$ Wolfgang W. Weisser, ${ }^{2}$ Roland Brandl, ${ }^{1}$ and Martin Brändle ${ }^{1}$ \\ ${ }^{1}$ Department of Ecology-Animal Ecology, Faculty of Biology, Philipps-Universität Marburg, \\ Karl-von-Frisch Straße 8, 35032 Marburg, Germany \\ ${ }^{2}$ Terrestrial Ecology Research Group, Department of Ecology and Ecosystem Management, TUM School of Life Sciences \\ Weihenstephan, Technische Universität München, Hans-Carl-von-Carlowitzplatz 2, 85350 Freising-Weihenstephan, Germany \\ ${ }^{3}$ Swiss Federal Research Institute WSL, Zürcherstrasse 111, 8903 Birmensdorf, Switzerland
}

\begin{abstract}
The nearly universal positive relationship between the distribution and abundance of species has been explained by several hypotheses but hitherto no consensus has been reached. Here, we used monitoring data of 105 phytophagous true bug species (Heteroptera) from 150 grassland sites over six years to test how (1) range position, (2) resource use, (3) resource availability, (4) density-dependent habitat selection, (5) metapopulation dynamics, and (6) habitat dispersal affect the distribution-abundance relationship. For the use in a confirmatory path analysis, we constructed causal pathways representing the hypothesized relationships and tested them separately and in a combined analysis. Our results show that the distributionabundance relationship in phytophagous true bugs is driven by habitat-availability. An increasing local density of the host-plants increases the distribution of the species in the landscape, which in turn increases their local abundance. Thereby habitat availability facilitates dispersal success. We conclude that local abundance of herbivores facing habitat destruction could decline owing to a decrease in population dynamics between sites at the landscape scale. Finally, our results underline the potential of confirmatory path analysis for testing competing hypotheses.
\end{abstract}

Key words: Biodiversity Exploratories; causality; distribution-abundance relationship; habitat availability; herbivores; Heteroptera; range position.

\section{INTRODUCTION}

The positive relationship between local abundance and spatial distribution of organisms is one of the classic patterns in macroecology (Hanski et al. 1993, Lawton 1999, Gaston et al. 2000, Holt et al. 2002, Blackburn et al. 2006, Borregaard and Rahbek 2010). This almost general relationship has been explained by several hypotheses, considering (1) range position, (2) resource use, (3) resource availability, (4) density-dependent habitat selection, (5) metapopulation dynamics, and (6) habitat dispersal (Fig. 1a-f; Borregaard and Rahbek 2010).

The range-position hypothesis suggests that the observed relationship between distribution and abundance does not reflect an ecological process per se but rather represents a sampling bias. The abundance and occupancy of a species declines for several mutually non-exclusive reasons with increasing distance to the center of the distributional range (Brown 1984). This intraspecific spatial relationship can lead to a positive interspecific relationship between distribution and abundance, if the study area covers different parts of species' ranges. The range-position hypothesis predicts that the interspecific pattern will disappear when we control for

Manuscript received 2 March 2017; revised 21 June 2017; accepted 23 June 2017. Corresponding Editor: Jay A. Rosenheim.

${ }^{4}$ E-mail: nico.friess@posteo.de differences in range position of species (Fig. 1a; Gaston et al. 2000). From a statistical point of view, the significance of the interspecific distribution-abundance relationship may also be biased by phylogeny (Gaston et al. 1997b), because phylogenetically related species have similar traits (Harvey and Pagel 1991). Consider for example two closely related groups of species one with a low abundance and a restricted distribution and the other showing high abundance and a broad distribution. Across the two groups a positive relationship becomes apparent, even when there is no relationship among species within each group. However, the idea has received no empirical evidence and several studies have found a significant positive distribution-abundance relationship even after controlling for phylogenetic relatedness (Blackburn et al. 1997, Gaston et al. 1997a, Quinn et al. 1997).

Other hypotheses explain the observed relationship with differences in ecological characteristics of the species and focus on the species' niche, specifically resource use (Fig. 1b; Brown 1984) and resource availability (Fig. 1c; Hutchinson 1957, Hanski et al. 1993). The resource-use hypothesis (Fig. 1b) proposes that species that utilize a broader spectrum of resources, e.g., an herbivorous insect feeding on several host plants, become both more widespread and abundant because of the higher probability of encountering a suitable resource in the landscape (Brown 1984, Kotze et al. 2003, Borregaard and Rahbek 2010). This would lead to a broader 
a) Range position hypothesis

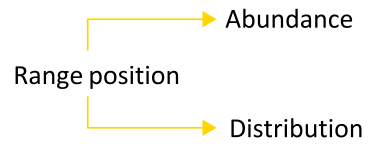

d) Density-dependent habitat selection

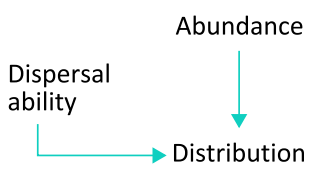

b) Resource-use hypothesis

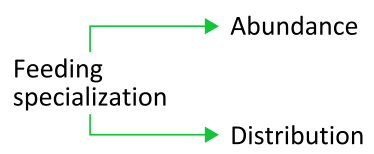

e) Metapopulation dynamics

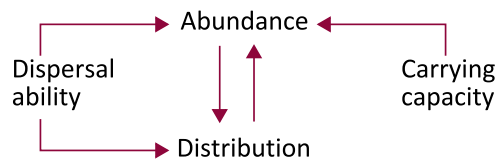

c) Resource-availability hypothesis

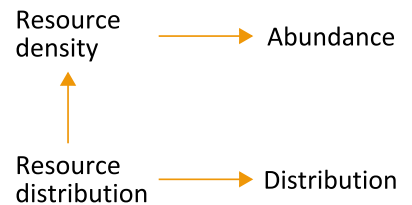

f) Habitat-dispersal hypothesis

FIG. 1. The causal pathways of the proposed explanations for the distribution-abundance relationship. Arrows indicate causal dependency. (a) The range-position hypothesis assumes that the distribution-abundance relationship vanishes when it is controlled for interspecific differences in range position. (b) The resource-use hypothesis assumes that feeding specialization acts as a latent variable controlling distribution and abundance. (c) The resource-availability hypothesis assumes that the abundance of the resource controls species' abundances and the distribution of the resource controls species' distributions. The hypothesis assumes no causal link between distribution and abundance. (d) Density-dependent habitat selection assumes that high abundances and high dispersal abilities increase the distribution of a species. (e) Metapopulation dynamics assume that distribution and abundance affect each other over time and space due to population dynamics. The strength of the relationship is driven by the dispersal ability of a species. The abundance of a species is additionally affected by the carrying capacity of the sites a species occupies. (f) The habitat-dispersal hypothesis assumes that the probability for successful colonization of a site increases with the local habitat availability, while the relationship between distribution and abundance is driven by population dynamics independent of the dispersal ability of a species. Thus, species with higher local habitat availability should exhibit larger distributions on a landscape scale and subsequently increase in abundance. Please note that these hypotheses are not mutually exclusive.

distribution and a higher abundance of generalists compared to specialists. The resource-availability hypothesis (Fig. 1c) states that species utilizing abundant and widespread resources can attain high abundances and broad distributions themselves, leading to the positive distribution-abundance relationship (Hanski et al. 1993, Borregaard and Rahbek 2010). Of course the resourceavailability hypothesis and resource-use hypothesis are closely related, but each places the emphasis on different aspects of the resource: resource utilization and resource distribution. Nevertheless, both hypotheses do not assume a direct causal link between distribution and abundance and rather expect resource use or availability to act as a latent variable controlling both variables separately (Fig. 1b, c). Consequently, these hypotheses do not predict a decrease in local abundance if species' distributions decrease and vice versa.

By contrast, other hypotheses assume direct causal links between local distribution and abundance and predict closely coupled dynamics between both variables (Fig. 1d-f; Borregaard and Rahbek 2010). O'Connor (1987) proposed density-dependent habitat selection (Fig. 1d) as a potential mechanism that leads to a positive relationship between distribution and abundance. For species that reach high densities, some individuals will colonize low-quality habitats, thus leading to an increase in the regional distribution (cf. ideal free distribution, Fretwell and Lucas 1969). Hence, the distribution is directly dependent on local abundance (Fig. 1d). This effect should be stronger for species with high dispersal abilities, which would lead to an independent positive effect of the propensity for dispersal on distribution (Fig. 1d). However, evidence for the importance of this mechanism is limited (but see: O'Connor 1987, Wiens et al. 1987, Marshall and Frank 1995).

A positive distribution-abundance relationship is also predicted by metapopulation models that incorporate carrying capacity and rescue effects (Hanski 1991, Nee et al. 1991, Gaston et al. 1997b). These models assume that the carrying capacities of habitats differ among species with some species being able to maintain larger local population sizes, which decreases their extinction probability and increases the number of colonizing individuals (Nee et al. 1991). Furthermore rescue effects decrease the probability of local extinction with increasing immigration, which also leads to more occupied patches (Hanski 1991, Gyllenberg and Hanski 1992, Hanski and Gyllenberg 1993, Hanski et al. 1993). Focusing on this simple assumption, Gyllenberg and Hanski (1992) predicted that species with high dispersal rates should occupy more patches within a landscape than species that are less dispersive at the same levels of local abundance (Fig. 1e; Hanski et al. 1993). If resource use or availability affects the local carrying capacity of a species, we expect that this relationship will be stronger for generalists and for species with high resource availability, and thus lead to positive independent effects of resource use or availability on species' mean abundance (Fig. 1e).

In this context, Venier and Fahrig (1996, 1998) proposed a framework where the interplay of habitat 
availability and dispersal dynamics can generate a positive distribution-abundance relationship even if the assumptions of metapopulation models are false. This habitatdispersal hypothesis (Fig. 1f) suggests that the dynamic mechanisms proposed by Gyllenberg and Hanski (1992) can lead to a positive distribution-abundance relationship independent of the dispersal ability of a species when dispersal success is determined by the amount of available habitat in a landscape (Venier and Fahrig 1996, 1998). The habitat-dispersal hypothesis thus assumes a dynamic causal interdependency of dispersal and abundance, but predicts that this relationship is independent of the propensity for dispersal of a species and rather assumes species' distributions to increase with local habitat amount (Fig. 1f). This relationship between habitat amount and species' distribution should be stronger for high-quality habitats than for low-quality habitats.

In the present study, we analyzed the distributionabundance relationship of phytophagous true bug species (Heteroptera) sampled in a long-term monitoring project in managed grasslands located in three regions of Germany. Herbivorous true bugs are a comparatively species-rich insect taxon in grasslands (Morris 1979). They vary considerably in local abundance and range from monophagous species that feed on only one host plant (e.g., Catoplatus fabricii, Tingidae; host plant Leucanthemum vulgare) to polyphagous species that feed on a wide range of host plants (e.g., Lygus rugulipennis, Miridae; known to feed on $\sim 400$ plant species of five families). Furthermore, the host plants of herbivorous true bugs in Central Europe are comparatively well known, which allows us to test hypotheses related to the resource and habitat availability of the species.

We expected that true bugs will show a positive distribution-abundance relationship as previously shown for numerous other insect taxa (Borregaard and Rahbek
2010). We analyzed the relationship considering the distinct causal relationships predicted by the above-mentioned six hypotheses (Fig. 1a-f). Since these hypotheses need not be mutually exclusive we tested each of the hypotheses separately (Fig. 1), as well as in a combined framework including all causal pathways predicted by the hypotheses (Fig. 2).

\section{Methods \\ Study sites}

Our study was conducted within the Biodiversity Exploratories (for detailed information, see Fischer et al. 2010). In this project, three exploratories were established for long-term research. The exploratories are situated in three geographic regions of Germany, namely the UNESCO Biosphere Reserve Schwäbische Alb (Swabian Jura, 48 $20^{\prime} 28^{\prime \prime} 48^{\circ} 32^{\prime} 02^{\prime \prime} \mathrm{N}, 9^{\circ} 10^{\prime} 49^{\prime \prime} 09^{\circ} 35^{\prime} 54^{\prime \prime} \mathrm{E}$, $\sim 422 \mathrm{~km}^{2}, 460-860 \mathrm{~m}$ above sea level), the UNESCO Biosphere Reserve Schorfheide-Chorin (52 47 $25^{\prime \prime} 53^{\circ} 13^{\prime} 26^{\prime \prime}$ $\mathrm{N}, 13^{\circ} 23^{\prime} 27^{\prime \prime} 14^{\circ} 08^{\prime} 53^{\prime \prime} \mathrm{E}, \sim 1,300 \mathrm{~km}^{2}, 3-140 \mathrm{~m}$ above sea level), and the National Park Hainich and surrounding Dün-region ( $50^{\circ} 56^{\prime} 14^{\prime \prime} 51^{\circ} 22^{\prime} 43^{\prime \prime} \mathrm{N}, 10^{\circ} 10^{\prime} 24^{\prime \prime} 10^{\circ} 46^{\prime} 45^{\prime \prime} \mathrm{E}$, $\sim 1,300 \mathrm{~km}^{2}, 285-550 \mathrm{~m}$ above sea level). In each region, experimental plots $(50 \times 50 \mathrm{~m})$ within a larger grassland site were chosen from a total of 500 candidate sites $(100 \times 100 \mathrm{~m}$ grid $)$ by stratified random sampling. This was done to minimize confounding factors such as spatial position or soil type and ensured that the plots covered the whole range of management types of the region. Minimum distance between grassland sites was $200 \mathrm{~m}$. Each grassland site is located within a larger management unit (94 \pm 10 ha [mean $\pm \mathrm{SE}$, range 5-800 ha) of a grassland complex, which has a history of broadly similar land-use intensity.

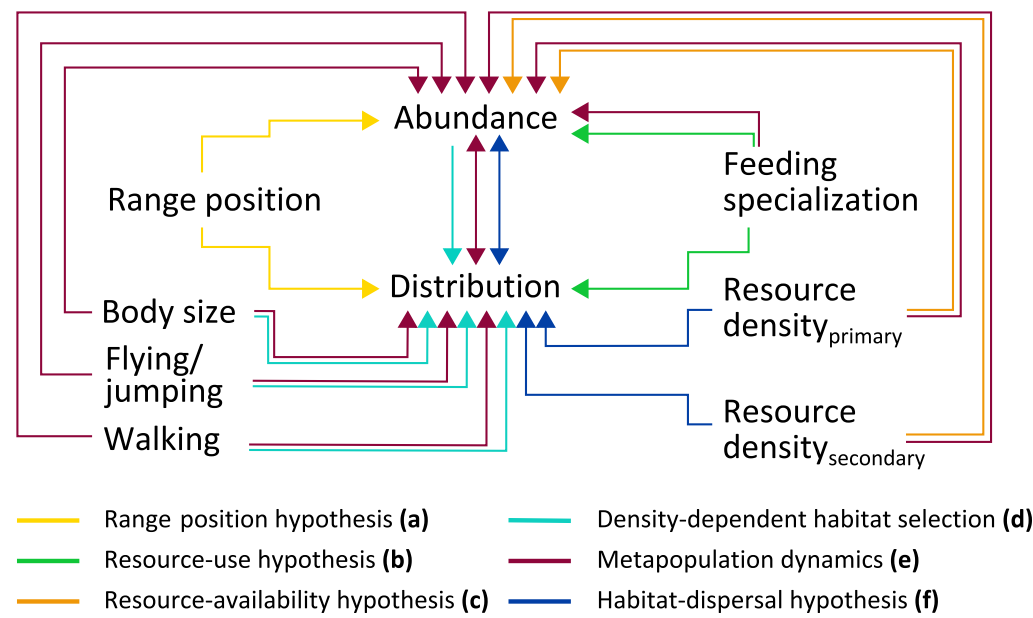

FIG. 2. Conceptual framework for the confirmatory path analysis including all paths assumed by the different hypotheses. Arrow tips indicate causal direction. Differently colored arrows indicate the hypotheses as depicted in the legend in the lower part of the figure. The subscripts "primary" and "secondary" refer to the primary and secondary host plants of the true bug species (see Methods section). Please note that these hypotheses are not mutually exclusive. 


\section{True bug abundance and local distribution}

The relative abundance of true bugs was assessed between 2008 and 2013 using standardized sweep netting (a total of 60 double sweeps along three 50-m plot border transects of each experimental plot within a larger grassland site). True bugs were sampled during dry periods in June and August (Simons et al. 2014, 2015). We considered only herbivorous species that utilize herbaceous plants and shrub species as main food resource; omnivorous species that use plant and animal food resources at about equal proportions were excluded. We excluded soil living species because sweep netting is likely to underestimate species abundance. Furthermore we excluded also species restricted to trees because these species occur only accidently in grasslands. The distribution of a species within each exploratory was estimated according to the proportion of occupied plots during at least one year of the sampling period. The mean abundance of a species across plots of each exploratory was estimated by dividing the total number of sampled individuals over the six sampling years by the number of occupied plots and is therefore a measure for the density of a species. We included 105 species (Alb, $n=77$; Hainich, $n=69$; and Schorfheide, $n=64$ ) in our analyses. For statistical analyses, the mean abundance was $\log _{e^{-}}$ transformed and the local distribution was logit-transformed (Borregaard and Rahbek 2010).

\section{Range position}

Based on data from the literature, we generated distribution maps for each species for the Palearctic and calculated the centroid of the range (Appendix S1: Fig. S1, Data S1). Afterward we calculated the distances between the centroid and the three regions using the haversine formula (Sinnott 1984). Since the distance to the centroid of the range is a function of the range size, we used the residuals of the linear relationship between the two variables as a corrected measure for the range position (Appendix S1: Fig. S2).

\section{Propensity for dispersal}

Since no reliable measures for dispersal rates for true bugs are currently available, we used already published morphological data as indicators for the propensity of dispersal (Gossner et al. 2015b). Morphological traits are often highly correlated with dispersal ability; however, results should be interpreted with caution (Sekar 2012). For all considered true bug species, we included body volume (i.e., as biovolume: body length $\times$ body width $\times$ body height; Siemann et al. 1999), hind femur length, hind femur width and, wing length as morphometric traits most likely linked to the propensity of dispersal (Clobert et al. 2012). Morphometric measures show allometric relationships; therefore, we performed a principal component analysis on the covariance matrix of the $\log _{e}$-transformed measures to obtain uncorrelated estimates. We extracted three principal components using the rda function implemented in the vegan package (Oksanen et al. 2015). In the following, we will use the terms body size, flying/jumping ability, and walking ability to refer to the three extracted components (for details, see Appendix S1). For body size, larger values indicate larger-bodied species; for flying/jumping ability, larger values indicate better flying and jumping abilities; and for walking ability, larger values indicate better walking abilities.

\section{Resource-use}

Information on the host plant utilization mode was derived from a published data set (Gossner et al. 2015a). From these data, we classified species as monophages, i.e., species feeding on plant species of one genus (14 of 105 species); oligophages, i.e., species feeding on plants of one higher lineage (55 of 105 species), specifically bryophytes, ferns, gymnosperms, angiosperms: monocots, angiosperms/basal eudicots, angiosperms/eurosids, and angiosperms/euasterids; and polyphages, i.e., species feeding on plants of more than one higher lineage (36 of 105 species; Gossner et al. 2015a). Although the variable measuring the breadth of host use has only three ordered values, we considered the variable to be continuous ranging from 1 (polyphagous) to 3 (monophagous).

\section{Resource availability}

Information on distribution and abundance of potential host plants based on vegetation relevés (ground cover estimation to the nearest percent on $4 \times 4 \mathrm{~m}$, following Wisskirchen and Haeupler [1998]) was extracted from annual field surveys in the Biodiversity Exploratories (Socher et al. 2012, 2013). The corresponding host plants of the true bug species were derived from the literature (see Appendix S1 and Data S2). We considered measures of resource density and resource occupancy in our analysis. Resource occupancy refers to the proportion of sites in which at least one host plant occurred in at least one year between 2008 and 2013. Resource density refers to the mean ground cover of the potential host plants across the years 2008-2013 on sites where the true bug species occurred. For statistical analyses, resource densities were $\log _{\mathrm{e}}$-transformed and resource occupancies were logit-transformed. All measures were separately calculated for primary host plants of a species (in the following indicated by the subscript primary) and for secondary host plants (host plants that are exploited only occasionally; in the following indicated by the subscript secondary), as categorized in the literature. This is necessary, since information on secondary host plants is often very vague and frequently only available on a genus or family level and therefore might lead to an overestimation of the habitat availability of the species. Primary host plants better represent 
the crucial habitat of the species, in the sense that these species are utilized as a feeding source but also more likely as a breeding ground and for oviposition. Secondary host plants are less frequently used by a particular species and mostly by adults. Thus the density of primary host plants offers better representations of the overall habitat of the species as assumed by the hypotheses linked to metapopulation dynamics and habitat dispersal.

\section{Confounding effect of land-use intensity}

A previous study in our study regions indicated that land-use intensity of managed grasslands affects the shape of species abundance distributions of arthropods (Simons et al. 2015). With high land-use intensities, rare species tend to become rarer, while the most abundant species become more dominant. Since our study sites exhibit a gradient in land-use intensity, we also considered land-use intensity as a confounding factor of the abundance patterns of species. For our study sites, information is available on the management intensities estimated by a composite land-use intensity index (for details see Blüthgen et al. 2012). Briefly, this index sums for each site the intensity of mowing, grazing, and fertilization into a continuous, regionally standardized value. We calculated the mean land-use intensity index for 2006-2013 for the sites occupied by a true bug species, as the species niche position along the land-use gradient. We tested for the effect of the mean land-use intensity on distribution and abundance separately and in the combined framework. Since land-use intensity had no significant effect on distribution or abundance in both analyses, we excluded the variable in the main analysis (Appendix S1: Table S5). This was additionally based on the fact, that there is currently no established hypothesis in the literature linking land-use intensity to the distribution-abundance relationship.

\section{Statistical analyses}

All statistical analyses were performed using the statistical software R, version 3.00.0 (R Core Team 2013). Our final data set included information on 105 true bug species on 150 sites for 2008-2013 (for the full species list, see Data S3). The probability distributions of the variables were checked and transformed when necessary to meet the assumptions of the statistical tests applied (Appendix S1: Table S2). The relationship between mean abundance ( $\log _{e}$-transformed) and local distribution (logit-transformed) was tested via linear regression for each exploratory. The outlined hypotheses make distinct predictions on the causal relationships among the variables (Fig. 1). We formulated structural equations representing the predictions for each hypothesis separately in order to test for the likelihood of each piecewise structural equation model (Table 1). All variables were centered and scaled in order to get comparable parameter estimates. The structural equations were formulated as linear mixed models using the lmer function implemented in the R package lme4 (Bates et al. 2013). For each predictor variable, we calculated the variance inflation factor (VIF) using a slightly modified version of the vif function implemented in the $\mathrm{R}$ package car (Fox and Weisberg 2011). Following the recommendations of Zuur et al. (2010) predictor variables with a variance inflation factor $>2$ were considered to cause multicollinearity effects and were subsequently dropped from the model in order to evaluate how their inclusion affects the parameter estimates. In the mixed models, we included the genus and the species identity as a nested random effect. With genus and species identity as a nested random effect, we can account for introduced extra variance by non-independent differences among genera and species, such as phylogenetic relatedness, and the replication of species among the three study regions (Harrison 2014). In order to test the hypothesis linked to metapopulation dynamics we included a link from the feeding specialization, as well as the host-plant densities on the mean abundance of the species, representing the carrying capacity of a site (Fig. 1e; Table 1). As an estimate for the local habitat availability in the context of the habitat-dispersal hypothesis, we included a link from the host-plant densities on the distribution of the species (Fig. 1f, Table 1). In this context, the densities of primary and secondary host plants represent the amount of high- and low-quality habitats, respectively. Since the outlined hypotheses need not be mutually exclusive, we additionally formulated a model of structural equations including all hypotheses (Fig. 2, Table 1). Due to the obvious collinearity among the variables, resource density and resource distribution we only included resource density in the model of the combined framework (Table 1). The dependency claims of each model were tested for statistical support using Shipley's test of d-separation for piecewise structural equation models as implemented in the piecewiseSEM package (Shipley 2009, 2013, Lefcheck 2015). The models of each hypothesis were then compared by their goodness-of-fit using $\mathrm{AIC}_{\mathrm{c}}$ and the chi-square test on Fischer's C (Shipley 2013). All models were tested once considering and once omitting polyphagous true bug species to test for consistency, taking into consideration that the information on the host plants of polyphagous species is less likely to be reliable compared to information available for monophages and oligophages.

\section{Results}

In all three study regions, we found a strong positive, bivariate relationship between mean abundance and local distribution (Alb, $r^{2}=0.74, P<0.001$; Hainich, $r^{2}=0.68, P<0.001$; Schorfheide, $r^{2}=0.74, P<0.001$; Fig. 3). All six hypotheses were tested with piecewise structural equation models representing their causal structure outlined in Figs. 1, 2. 
TABLE 1. Structural equations used in the piecewise structural equation models.

\begin{tabular}{|c|c|c|c|c|c|c|c|c|}
\hline Model and response & Structural equations & $R_{\mathrm{M}}^{2}$ & $R_{\mathrm{C}}^{2}$ & $C$ & df & $P$ & $\mathrm{AIC}_{\mathrm{c}}$ & $K$ \\
\hline \multicolumn{9}{|l|}{$\mathrm{a}$} \\
\hline Abundance & $\sim$ range position & $<0.01$ & 0.66 & 205.7 & 2 & $<0.001$ & 226.8 & 10 \\
\hline $\begin{array}{l}\text { Distribution } \\
\mathrm{b}\end{array}$ & $\sim$ range position & 0.02 & 0.70 & & & & & \\
\hline Abundance & $\sim$ feeding specialization & $<0.01$ & 0.67 & 205.0 & 2 & $<0.001$ & 226.2 & 10 \\
\hline $\begin{array}{l}\text { Distribution } \\
\mathrm{c}\end{array}$ & $\sim$ feeding specialization & 0.01 & 0.71 & & & & & \\
\hline Abundance & $\sim$ resource density $y_{\text {primary }}+$ resource density secondary & 0.56 & 0.78 & 377.6 & 16 & $<0.001$ & 427.0 & 22 \\
\hline Distribution & $\sim$ resource distribution primary + resource distribution $_{\text {secondary }}$ & 0.18 & 0.73 & & & & & \\
\hline $\begin{array}{l}\text { Resource } \\
\text { density }_{\text {primary }}\end{array}$ & $\sim$ resource distribution primary & 0.40 & 0.83 & & & & & \\
\hline $\begin{array}{l}\text { Resource } \\
\text { density } \\
\text { d }\end{array}$ & $\sim$ resource distribution ${ }_{\text {secondary }}$ & 0.58 & 0.90 & & & & & \\
\hline Distribution & $\begin{array}{l}\text { abundance }+ \text { body size }+ \text { flying/jumping ability } \\
+ \text { walking ability }\end{array}$ & 0.70 & 0.86 & & & & 311.7 & \\
\hline \multicolumn{9}{|c|}{ 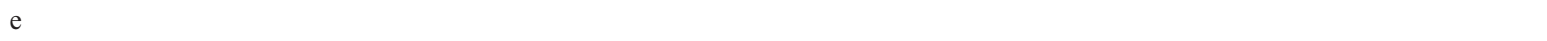 } \\
\hline Abundance & $\begin{array}{l}\text { - distribution + resource density } \text { primary } \\
\text { + resource density secondary body size } \\
\text { + flying/jumping ability + walking ability } \\
\text { + feeding specialization }\end{array}$ & 0.73 & 0.84 & 87.3 & 6 & $<0.001$ & 129.3 & 19 \\
\hline Distribution & $\begin{array}{l}\text { abundance }+ \text { body size }+ \text { flying/jumping ability } \\
+ \text { walking ability }\end{array}$ & 0.70 & 0.86 & & & & & \\
\hline \multicolumn{9}{|c|}{ 皮 } \\
\hline Abundance & $\sim$ distribution & 0.72 & 0.84 & 8.5 & 4 & 0.08 & 34.1 & 12 \\
\hline $\begin{array}{l}\text { Distribution } \\
\text { All }\end{array}$ & $\sim$ resource density $y_{\text {primary }}+$ resource density $_{\text {secondary }}$ & 0.80 & 0.91 & & & & & \\
\hline Abundance & $\begin{array}{l}\text { - distribution }+ \text { body size }+ \text { flying/jumping ability } \\
+ \text { walking ability }+ \text { feeding specialization } \\
+ \text { resource density secondary }+ \text { range position }\end{array}$ & 0.72 & 0.84 & 3.4 & 2 & 0.18 & 55.4 & 23 \\
\hline Distribution & $\begin{array}{l}\text { abundance }+ \text { body size }+ \text { flying/jumping ability } \\
+ \text { walking ability }+ \text { feeding specialization } \\
+ \text { resource density } \\
+ \text { range positionary }+ \text { resource density }\end{array}$ & 0.81 & 0.91 & & & & & \\
\hline
\end{tabular}

Notes: Model refers to the corresponding hypotheses in Figs. 1,2. All models included genus and species identity as a nested random factor. The related hypotheses are as follows, (a) range-position hypothesis, (b) resource-use hypothesis, (c) resource-availability hypothesis, (d) density-dependent habitat selection, (e) metapopulation dynamics, (f) habitat-dispersal hypothesis and (all) all hypotheses combined (Fig. 5). Reported statistics include marginal $R^{2}\left(R_{\mathrm{M}}^{2}\right)$, conditional $R^{2}\left(R_{\mathrm{C}}^{2}\right)$, Fisher's $C$, the chi-squared test degrees of freedom (df), $P$-value of the Chi-squared significance test, $\mathrm{AIC}_{\mathrm{c}}$ value $\left(\mathrm{AIC}_{\mathrm{c}}\right)$ and the likelihood degrees of freedom $(K)$. Note that model (d) is based on a regular linear mixed effect model and thus the statistics for piecewise structural equation models are not available (see Results). The subscript "primary" and "secondary" refers to primary and secondary host plants (see Methods).

Model a.-Concerning the range-position hypothesis (model a), we did not find an effect of species' range position on its mean abundance or local distribution (Table 1, Fig. 4a) and the model consequently had no statistical support based on the chi-square test on Fisher's $C(C=193.7$, df $=2, P<0.001$; Table 1$)$.

Model b.-Concerning the resource-use hypothesis (model b), species' feeding specialization did not affect its mean abundance and local distribution (Table 2, Fig. 4b) and thus the model was not supported $(C=205.0, \mathrm{df}=2, P<0.001$; Table 1$)$.

Model c.-Concerning the resource availability hypothesis (model c), we found significant positive effects of resource distribution on resource density, as well of resource density on species' mean abundance and of resource distribution on species' local distribution (Table 2, Fig. 4c). The overall model was, however, not statistically supported $(C=377.6, \mathrm{df}=16, P<0.001)$.

Model $d$ - Concerning the hypothesis related to density dependent habitat selection (model d), we found a highly significant positive effect of species' mean abundance on its local distribution and a weak positive effect of walking ability on species' distribution, but no significant effects of body size and flying/jumping ability on species' local distribution (Table 2, Fig. 4d). Since, this hypothesis could not be modeled as an acyclic path diagram, we could not perform a test on Fisher's $C$. In comparison to the other models, we found a very high $\mathrm{AIC}_{\mathrm{c}}$ value, suggesting a weak fit (Table 1). 


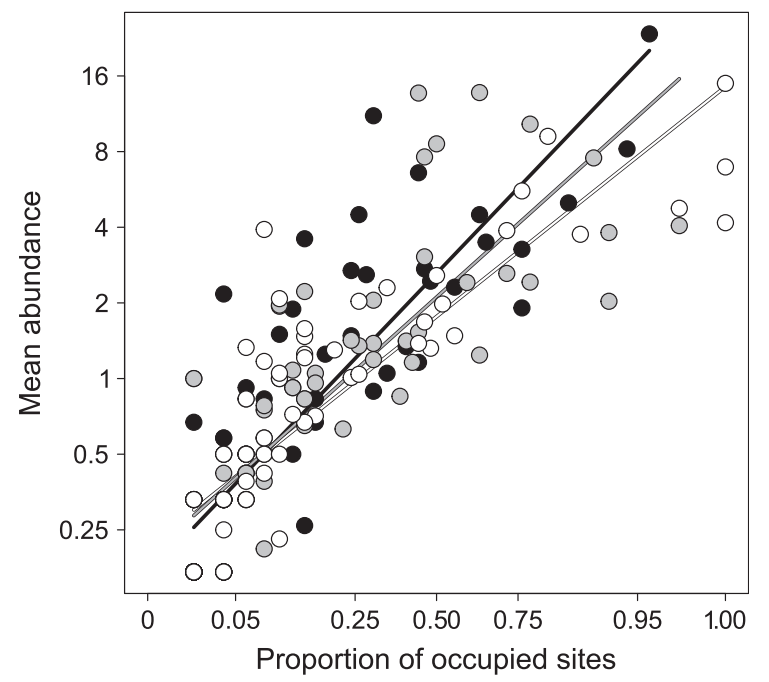

FIG. 3. The positive relationship between mean abundance and the proportion of occupied sites for true bug species in the three regions Schwäbische Alb (black filled circles and line; linear model, $r^{2}=0.74, P<0.001, n=77$ ), Hainich (gray filled circles and line; linear model, $r^{2}=0.68, P<0.001, n=69$ ) and Schorfheide-Chorin (open circles and line; linear model, $\left.r^{2}=0.74, P<0.001, n=64\right)$. Note that mean abundance was $\log _{e}$-transformed and the proportion of occupied sites was logittransformed.

Model e.-Concerning the hypothesis representing metapopulation dynamics (model e), we found significant effects of species' mean abundance and local distribution on the respective other. Resource density and species' feeding specialization, representing the carrying capacity the species encountered on the sites, had no significant effect on species' mean abundance. The variables linked to species' dispersal propensity had no significant effect on its mean abundance or local distribution except for a weak positive effect of the walking ability on species' distribution (Fig. 4e, Table 2). The overall model, however, was not supported according to the chi-square test on Fisher's $C(C=87.3, \mathrm{df}=6$, $P<0.001$; Table 1). In this model, the variance inflation factors of species' local distribution and resource density of the primary host plants exceeded the critical value of 2. Thus, we calculated the model again excluding the resource density of the primary host plant. The variance inflation factor of species' local distribution decreased with the removal of resource density, indicating collinearity between these two variables as confirmed below. The removal, however, did not change the result that the overall model was not supported $(C=12.9$, $\mathrm{df}=4, P<0.05)$.

Model f.-Concerning the model representing the habitat-dispersal hypothesis (model f), we found significant positive effects of species' mean abundance and local distribution on the respective other. Furthermore, we found significant positive effects of resource densities of primary and secondary host plants on the species' local distribution. Here, we found the greatest effect size from the density of the primary host plant on species' local distribution. This effect was even stronger than the one from species' mean abundance on its local distribution. Notably, the model revealed a much stronger effect from species' local distribution on its mean abundance, than a) Range position hypothesis

${ }_{1----\rightarrow} \rightarrow$ Abundance

Range position

$(----\rightarrow$ Distribution

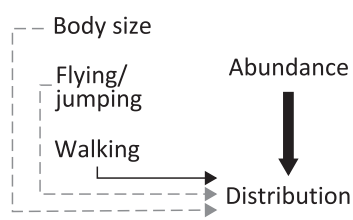

b) Resource-use hypothesis

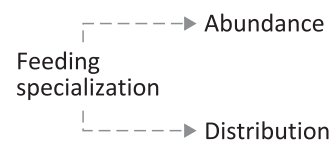

c) Resource-availability hypothesis

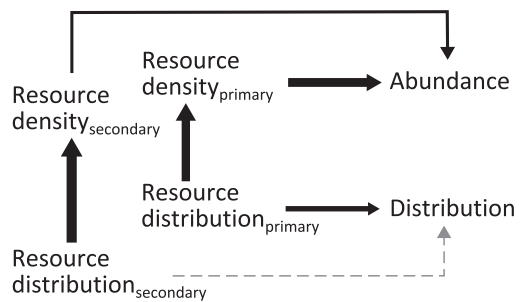

f) Habitat-dispersal hypothesis

FIG. 4. Results of the piecewise structural equation models separately for each hypothesis. Heavy arrows indicate significant effects, dashed arrows indicate non-significant effects. Arrow thickness is adjusted according to the standardized effect size (Table 2). The subscripts "primary" and "secondary" refer to the primary and secondary host plants of the true bug species (see Methods). 
TABLE 2. Results from the piecewise structural equation modelling, including standardized effect sizes (SES), standard errors (SE), $P$ values, and the variance inflation factor (VIF).

\begin{tabular}{|c|c|c|c|c|c|}
\hline Model and response & Predictor & SES & SE & $P$ & VIF \\
\hline \multicolumn{6}{|l|}{$\mathrm{a}$} \\
\hline Mean abundance & range position & -0.10 & 0.08 & 0.18 & 1.00 \\
\hline $\begin{array}{l}\text { Local distribution } \\
\mathrm{b}\end{array}$ & range position & -0.04 & 0.08 & 0.63 & 1.00 \\
\hline Mean abundance & feeding specialization & -0.06 & 0.08 & 0.51 & 1.00 \\
\hline Local distribution & feeding specialization & -0.09 & 0.08 & 0.27 & 1.00 \\
\hline \multicolumn{6}{|l|}{$\mathrm{c}$} \\
\hline Mean abundance & resource density primary & 0.66 & 0.06 & $<0.001$ & 1.16 \\
\hline Mean abundance & resource density secondary & 0.21 & 0.06 & $<0.01$ & 1.16 \\
\hline Local distribution & resource distribution $_{\text {primary }}$ & 0.34 & 0.06 & $<0.001$ & 1.03 \\
\hline Local distribution & resource distribution ${ }_{\text {secondary }}$ & 0.09 & 0.07 & 0.23 & 1.03 \\
\hline Resource density primary & resource distribution $_{\text {primary }}$ & 0.53 & 0.05 & $<0.001$ & 1.00 \\
\hline $\begin{array}{l}\text { Resource density } y_{\text {secondary }} \\
\text { d }\end{array}$ & resource distribution $_{\text {secondary }}$ & 0.68 & 0.05 & $<0.001$ & 1.00 \\
\hline Local distribution & mean abundance & 0.70 & 0.05 & $<0.001$ & 1.10 \\
\hline Local distribution & body size & 0.08 & 0.04 & 0.10 & 1.03 \\
\hline Local distribution & flying/jumping ability & 0.01 & 0.05 & 0.77 & 1.01 \\
\hline \multicolumn{6}{|l|}{ e } \\
\hline Mean abundance & local distribution & 0.73 & 0.07 & $<0.001$ & 3.02 \\
\hline Mean abundance & resource density primary & 0.11 & 0.08 & 0.17 & 2.93 \\
\hline Mean abundance & resource density & 0.09 & 0.05 & 0.11 & 1.28 \\
\hline Mean abundance & feeding specialization & 0.02 & 0.05 & 0.71 & 1.17 \\
\hline Mean abundance & body size & -0.02 & 0.05 & 0.65 & 1.24 \\
\hline Mean abundance & flying/jumping ability & -0.03 & 0.05 & 0.47 & 1.01 \\
\hline Mean abundance & walking ability & 0.03 & 0.05 & 0.54 & 1.18 \\
\hline Local distribution & mean abundance & 0.70 & 0.04 & $<0.001$ & 1.10 \\
\hline Local distribution & body size & 0.08 & 0.05 & 0.10 & 1.03 \\
\hline Local distribution & flying/jumping ability & 0.01 & 0.05 & 0.77 & 1.01 \\
\hline Local distribution & walking ability & 0.10 & 0.05 & 0.06 & 1.08 \\
\hline \multicolumn{6}{|l|}{ f } \\
\hline Mean abundance & local distribution & 0.85 & 0.04 & $<0.001$ & 1.00 \\
\hline Local distribution & mean abundance & 0.43 & 0.04 & $<0.001$ & 1.89 \\
\hline Local distribution & resource density primary & 0.45 & 0.05 & $<0.001$ & 1.82 \\
\hline Local distribution & resource density secondary & 0.11 & 0.04 & $<0.01$ & 1.18 \\
\hline \multicolumn{6}{|l|}{ All } \\
\hline Mean abundance & local distribution & 0.81 & 0.05 & $<0.001$ & 1.35 \\
\hline Mean abundance & range position & 0.04 & 0.05 & 0.41 & 1.19 \\
\hline Mean abundance & feeding specialization & -0.01 & 0.05 & 0.96 & 1.24 \\
\hline Mean abundance & resource density secondary & 0.09 & 0.05 & 0.09 & 1.30 \\
\hline Mean abundance & body size & -0.01 & 0.05 & 0.91 & 1.19 \\
\hline Mean abundance & flying/jumping ability & -0.03 & 0.05 & 0.52 & 1.04 \\
\hline Mean abundance & walking ability & 0.03 & 0.05 & 0.54 & 1.18 \\
\hline Local distribution & mean abundance & 0.43 & 0.04 & $<0.001$ & 1.88 \\
\hline Local distribution & range position & -0.05 & 0.04 & 0.19 & 1.14 \\
\hline Local distribution & feeding specialization & 0.02 & 0.04 & 0.71 & 1.23 \\
\hline Local distribution & resource density $_{\text {primary }}$ & 0.47 & 0.05 & $<0.001$ & 1.91 \\
\hline Local distribution & resource density secondary & 0.10 & 0.05 & $<0.05$ & 1.26 \\
\hline Local distribution & body size & -0.05 & 0.05 & 0.24 & 1.22 \\
\hline Local distribution & flying/jumping ability & 0.02 & 0.04 & 0.58 & 1.03 \\
\hline Local distribution & walking ability & 0.07 & 0.04 & 0.12 & 1.12 \\
\hline
\end{tabular}

Notes: Lowercase letters for models correspond to the structural equations in Table 1 and the path diagrams in Figs. $4,5$. Significant effects are in boldface type. The subscript "primary" and "secondary" refers to primary and secondary host plants (see Methods). 
the other way around (Table 2, Fig. 4f). Here, the overall model was statistically supported $(C=8.5$, df $=4$, $P=0.08$; Table 1).

Comparing the $\mathrm{AIC}_{\mathrm{c}}$ values of the six models revealed that the model representing the habitat-dispersal hypothesis (model $\mathrm{f}$ ) performed best by several magnitudes and was the only model that was supported according to Fishers' $C$ (Table 1). The model including all causal pathways in a combined framework predicted by the six hypotheses revealed significant effects from mean abundance and local distribution on the respective other, as well as significant positive effects of the resource densities of the primary and secondary host-plants on the local distribution (Fig. 5, Table 2). As already shown for the model representing the habitat-dispersal hypothesis (Fig. 4f), the effect of distribution on abundance was much higher than the effect of abundance on distribution and the effect of the density of the primary host plants on distribution was stronger than the effect of mean abundance (Table 2). All other paths were not significant. The overall model was statistically supported ( $C=3.4$, df $=2, P=0.18$ ). It has to be considered that we had to remove the path from resource density of the primary host plants to mean abundance, due to its variance inflation factor exceeding a value of 2 . The test for the significance of the independence claims showed, however, that the path was not significant and hence justified its removal (SES $=0.11, \mathrm{SE}=0.08, P=0.18$ ). Removing all non-significant pathways from the model resulted in the model representing the habitat-dispersal hypothesis. The results of our analysis remained consistent when polyphagous species were excluded from the analysis (Appendix S1: Tables S3, S4).

\section{Discussion}

In our study, the best model (model f; Figs. 1, 2, 4) revealed two important relationships: (1) a strong effect of the density of the primary host plant on species' distribution and (2) the effect of distribution on abundance exceeding the effect of abundance on distribution. This suggests a mechanistic link from high habitat availabilities to broad distributions, which in turn leads to high local abundances. High abundances then feed back into higher distributions most probably by population dynamics among sites. Overall our results appear to be robust and reliable for several reasons; First, they were consistent when polyphagous species were removed from the analysis. Second, by including the genus and the species identity as a nested random effect in our analyses we accounted for similarities among species originating in the phylogenetic relatedness (Blackburn and Duncan 2001, Bolker et al. 2009). Third, we found low values of the variance inflation factor for the variables, indicating that our models are not affected by multicollinearity effect. To our knowledge, no published study is available that compared several hypotheses aiming to explain the distribution-abundance relationship simultaneously in a framework including causal relationships (Borregaard and Rahbek 2010). Before drawing major conclusions from our study, we will discuss why other hypotheses outlined in the introduction might not apply in our study system and do not account for the distributionabundance relationship.

The range-position hypothesis (Fig. 1a) proposes that a relationship of distribution and abundance might arise because the abundance of species and the number of occupied sites decline from the center to the border of the distributional range (Brown 1984). Interspecific differences in species' distances to the center of their distributional range could then lead to a positive distribution-abundance relationship. We found no evidence for an effect of the range position of species on the mean abundance or local distribution in our system. Grasslands in Central Europe almost always originated from human land use, which might have generated a sufficient number of suitable habitat patches even at the edge of the range of a species. This implies that the range-position hypothesis might apply only for systems with little or no human impact.

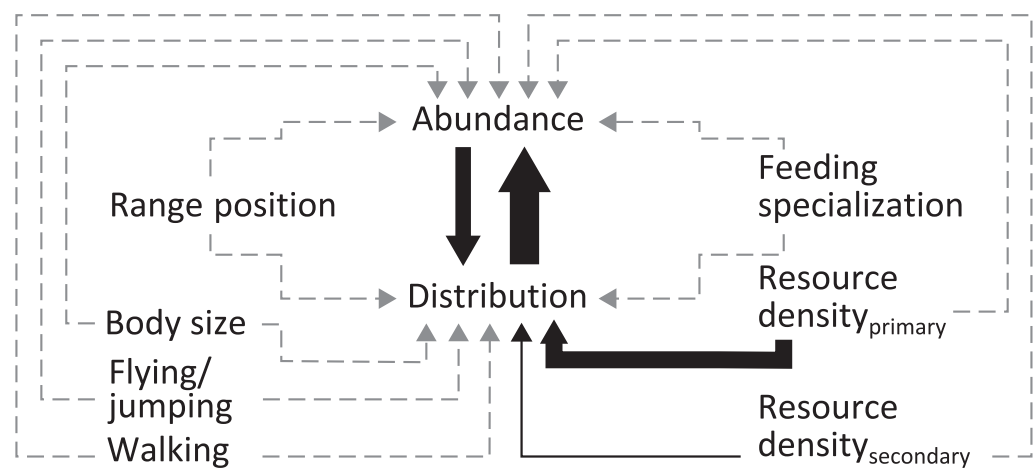

FIG. 5. Results of the piecewise structural equation model including the paths of all hypotheses as depicted in Fig. 2. Heavy arrows indicate significant effects, dashed arrows indicate non-significant effects. Arrow thickness is adjusted according to the standardized effect size (Table 2). The subscripts "primary" and "secondary" refer to the primary and secondary host plants of the true bug species (see Methods). 
Empirical evidence for the resource-use hypothesis (Fig. 1b) is weak and ambiguous (Gaston et al. 1997b; positive relationships, e.g., Barger and Esch 2002, Kotze et al. 2003, Heino 2005, Faulks et al. 2015; no relationship, Gaston and Lawton 1988, Root and Cappuccino 1992, Gregory and Gaston 2000, McCreadie and Adler 2014; negative relationships, Gaston et al. 1997b, Päivinen et al. 2005, Verberk et al. 2010). In our study, the degree of feeding specialization had no effect on either the local distribution or the mean abundance of a species. This suggests that there are not necessarily more resources available for generalists than for specialists on a regional scale (Venier and Fahrig 1996) or at least not in such a way that its effect could drive the relationship of distribution and abundance.

The resource-availability hypothesis (Fig. 1c) assumes that species utilizing widespread and abundant resources become themselves widespread and abundant (Gaston et al. 1997b, Borregaard and Rahbek 2010). The resource-availability is closely linked to the niche position of a species and the hypothesis has received some empirical support for various taxa, including stream insects (Heino 2005, but see McCreadie and Adler 2014), fish (Tales et al. 2004), and birds (Gregory and Gaston 2000). However, so far no study has shown that resource availability alone can generate the distributionabundance relationship (Borregaard and Rahbek 2010). In our study, we found positive effects of resource density on the abundance of true bug species, as well as positive effects of host plant distribution on the species' distribution. However, the overall model was not supported and it turns out, that rather host plant density affects the distribution of phytophages than their abundances. This instance might as well be overlooked when hypotheses are tested by linear models that do not test for the significance of the independence claims. This underlines the strength of the confirmatory path analysis approach.

Empirical support has been found for positive density-dependent habitat selection (Fig. 1d) for some taxa, including passerine birds (O'Connor 1987) and fish (Marshall and Frank 1995, Blanchard et al. 2005). Positive density-dependent habitat selection assumes a causal dependency from distribution on the abundance of the species mediated by their propensity for dispersal. Our results show a positive effect of mean abundance on species' distribution; however, morphological measures linked to the propensity of dispersal had no significant effect on mean abundance or local distribution and the model was not supported. Additionally, in the combined framework our model revealed a greater effect of distribution on abundance than vice versa, thus rendering it unlikely that density-dependent habitat selection alone shapes the distribution-abundance relationship for grassland true bugs.

Metapopulation dynamics models (Fig. 1e) predict a positive independent effect of dispersal ability on distribution or abundance or both, while the relationship between distribution and abundance persists (Hanski et al. 1993, Hanski 1999, Borregaard and Rahbek 2010). Furthermore, abundance is expected to be positively affected by the carrying capacity of the sites a species colonizes, which we assumed increases with local host plant density and decreases with species' feeding specialization. Metapopulations are formed in landscapes with isolated habitat patches, frequent extinctions of local populations, and colonization of empty habitats. There is some evidence for metapopulation dynamics shaping the relationship for some taxa, including microarthropods inhabiting mosses (Gonzalez et al. 1998), rockpool Daphnia (Östman 2010), and aquatic plants (Riis and Sand-Jensen 2002). However, it has been questioned whether most taxa exhibit metapopulation dynamics at regional scales (Borregaard and Rahbek 2010). In our study, the variables representing the carrying capacity for a species had no effect on the abundance of a species, while the propensity for dispersal was not related to distribution or abundance. This indicates that phytophagous true bugs might not be constrained by their dispersal ability. However, it is important to note that we did not directly measure the dispersal ability, but instead used morphological traits as proxies. A meta-analysis has shown, that the wingspan of butterflies is highly correlated to the dispersal ability, but its explanatory power was low (Sekar 2012). Nevertheless, a recent experimental study of red flour beetles (Tribolium castaneum) showed that dispersal is more strongly linked to morphological traits, namely leg length, than to physiological traits (e.g., metabolic rate [Arnold et al. 2017]).

The habitat-dispersal hypothesis (Fig. 1f) suggests that even a weak disperser can attain high densities and a wide distribution independent of the propensity for dispersal, when dispersal success is determined by the amount of available habitat in the landscape (Venier and Fahrig 1996, 1998, Fahrig 2013). Thus, high habitat availability should increase dispersal success and therefore increase the distribution of the species. The hypothesis is often compared to or treated as similar to the resource-availability hypothesis. However, despite the causal link between habitat density and the distribution, rather than the abundance of a species, Venier and Fahrig (1996) clearly link habitat availability to dynamic processes. Thus, the hypothesis does not expect habitat availability to solely account for the distribution-abundance relationship, but rather to explain the deviations from the relationship that itself is shaped by population dynamics (i.e., an independent effect of habitat availability on distribution). Such positive independent effects of habitat availability have been found for several taxa, including stream insects (Heino 2005, Tonkin et al. 2016), amphibians (Rannap et al. 2009), diatoms (Heino and Soininen 2006), birds (Gregory and Gaston 2000), and fish (Tales et al. 2004). Next to a positive independent effect of habitat availability on distribution, we additionally proposed that this effect should be stronger for habitats of higher quality, since increasing 
habitat quality should further facilitate dispersal success. In our study, the amount of available habitat was determined by the density of the potential host plants of a species, with primary and secondary host plants representing high-quality and low-quality habitats, respectively. While secondary host plants might be utilized for feeding, primary host plants are also more often used for oviposition in many phytophagous true bugs and thus represent the available habitat in a landscape more accurately. The predicted causal structure of the habitat-dispersal hypothesis is strongly supported. The density of host plants had an independent positive effect on the distribution of species, while the causal link between distribution and abundance remained. This independent effect was stronger for the primary host plants. The effect of primary host plant density even surpassed the effect of mean abundance on the distribution of a species. These results appear to be robust and persisted after the exclusion of polyphagous species. For herbivores, an increasing dispersal success on sites with higher densities of host plants is an expectation of the resource concentration hypothesis, which states that herbivores are most likely to find and remain in patches with high densities of its host plants (Root 1973, Ralph 1977).

\section{Conclusion}

Understanding the processes leading to a positive distribution-abundance relationship of species has far-reaching implications for conservation efforts, as Lawton (1996) points out: (1) species could face a "double jeopardy" when species with small range sizes also occur at low local densities, thereby increasing their vulnerability to human impacts, (2) a dynamic relationship between distribution and abundance might result in species not inhabiting all suitable habitats within its range when it occurs at low densities locally, and (3) human impacts that reduce the number of habitat sites regionally (e.g., habitat degradation or destruction) can reduce species densities even in remaining undisturbed sites, such as protected areas. Our study indicates that in order to maintain high abundances and broad distributions, herbivorous insects depend on high regional habitat availability. Thus, if the amount of suitable habitat decreases at the landscape scale, it might not be sufficient to protect single sites where species are locally abundant in order to prevent populations from going locally extinct. For the long-term facilitation of population dynamics, conservation efforts should aim at establishing sufficient high-quality sites with high densities of potential habitat. This would maintain high abundances of focal species and would reduce their extinction probabilities in a landscape. Efforts to increase habitat availability, however, require detailed knowledge of habitat requirements of a species, which should be a reminder for ecologists not to neglect autecological studies.

\section{ACKNOWLEDGMENTS}

We want to express our appreciation for the helpful comments of the handling editor and two anonymous reviewers that largely improved the manuscript. We thank the managers of the Biodiversity Exploratories and everyone involved. For extended acknowledgments, see Appendix S1. This work has been (partly) funded by the DFG Priority Program 1374 "Infrastructure-Biodiversity-Exploratories" (DFG-BR 1967/9-1, DFG-WE 3081/21-1). Field work permits were issued by the responsible state environmental offices of Baden-Württemberg, Thüringen, and Brandenburg (according to $\S 72 \mathrm{BbgNatSchG).} \mathrm{We} \mathrm{thank}$ Ms. Karen Brune for proofreading the manuscript as a native English speaker.

\section{Literature Cited}

Arnold, P. A., P. Cassey, and C. R. White. 2017. Functional traits in red flour beetles: the dispersal phenotype is associated with leg length but not body size nor metabolic rate. Functional Ecology 31:653-661.

Barger, M. A., and G. W. Esch. 2002. Host specificity and the distribution-abundance relationship in a community of parasites infecting fishes in streams of North Carolina. Journal of Parasitology 88:446-453.

Bates, D., M. Maechler, and B. Bolker. 2013. lme4: linear mixed-effects models using $\mathrm{S} 4$ classes. R package version 0.999999-2. http://CRAN.R-project.org/package=lme4

Blackburn, T. M., P. Cassey, and K. J. Gaston. 2006. Variations on a theme: sources of heterogeneity in the form of the interspecific relationship between abundance and distribution. Journal of Animal Ecology 75:1426-1439.

Blackburn, T. M., and R. P. Duncan. 2001. Determinants of establishment success in introduced birds. Nature 414:195-197.

Blackburn, T. M., K. J. Gaston, R. M. Quinn, H. Arnold, and R. D. Gregory. 1997. Of mice and wrens: the relation between abundance and geographic range size in British mammals and birds. Philosophical Transactions of the Royal Society B 352:419-427.

Blanchard, J. L., C. Mills, S. Jennings, C. J. Fox, B. D. Rackham, P. D. Eastwood, and C. M. O'Brien. 2005. Distribution-abundance relationships for North Sea Atlantic cod (Gadus morhua): observation versus theory. Canadian Journal of Fisheries and Aquatic Sciences 62:2001-2009.

Blüthgen, N., et al. 2012. A quantitative index of land-use intensity in grasslands: integrating mowing, grazing and fertilization. Basic and Applied Ecology 13:207-220.

Bolker, B. M., M. E. Brooks, C. J. Clark, S. W. Geange, J. R. Poulsen, M. H. H. Stevens, and J.-S. S. White. 2009. Generalized linear mixed models: a practical guide for ecology and evolution. Trends in Ecology \& Evolution 24:127-135.

Borregaard, M. K., and C. Rahbek. 2010. Causality of the relationship between geographic distribution and species abundance. Quarterly Review of Biology 85:3-25.

Brown, J. H. 1984. On the relationship between abundance and distribution of species. American Naturalist 124:255-279.

Clobert, J., M. Baguette, T. G. Benton, and J. M. Bullock. 2012. Dispersal ecology and evolution. First Edition. Oxford University Press, Oxford, United Kingdom.

Fahrig, L. 2013. Rethinking patch size and isolation effects: the habitat amount hypothesis. Journal of Biogeography 40: 1649-1663.

Faulks, L., R. Svanback, H. Ragnarsson-Stabo, P. Eklov, and O. Ostman. 2015. Intraspecific niche variation drives abundance-occupancy relationships in freshwater fish communities. American Naturalist 186:272-283. 
Fischer, M., et al. 2010. Implementing large-scale and longterm functional biodiversity research: the Biodiversity Exploratories. Basic and Applied Ecology 11:473-485.

Fox, J., and S. Weisberg. 2011. An R companion to applied regression. Second edition. Sage, Thousand Oaks, California, USA.

Fretwell, S. D., and H. L. Lucas. 1969. On territorial behavior and other factors influencing habitat distribution in birds. Acta Biotheoretica 19:16-36.

Gaston, K. J., T. M. Blackburn, J. J. D. Greenwood, R. D. Gregory, R. M. Quinn, and J. H. Lawton. 2000. Abundanceoccupancy relationships. Journal of Applied Ecology 37:39-59.

Gaston, K. J., T. M. Blackburn, and R. D. Gregory. 1997a. Abundance-range size relationships of breeding and wintering birds in Britain: a comparative analysis. Ecography 20: 569-579.

Gaston, K. J., T. M. Blackburn, and J. H. Lawton. 1997b. Interspecific abundance-range size relationships: an appraisal of mechanisms. Journal of Animal Ecology 66:579.

Gaston, K. J., and J. H. Lawton. 1988. Patterns in body size, population dynamics, and regional distribution of bracken herbivores. American Naturalist 132:662-680.

Gonzalez, A., J. H. Lawton, F. S. Gilbert, T. M. Blackburn, and I. Evans-Freke. 1998. Metapopulation dynamics, abundance, and distribution in a microecosystem. Science 281:2045-2047.

Gossner, M. M., N. K. Simons, R. Achtziger, T. Blick, W. H. Dorow, F. Dziock, F. Köhler, W. Rabitsch, and W. W. Weisser. 2015a. A summary of eight traits of Coleoptera, Hemiptera, Orthoptera and Araneae, occurring in grasslands in Germany. Scientific Data 2:150013.

Gossner, M. M., N. K. Simons, L. Höck, and W. W. Weisser. 2015b. Morphometric measures of Heteroptera sampled in grasslands across three regions of Germany. Ecology 96:1154

Gregory, R. D., and K. J. Gaston. 2000. Explanations of commonness and rarity in British breeding birds: separating resource use and resource availability. Oikos 88:515-526.

Gyllenberg, M., and I. Hanski. 1992. Single-species metapopulation dynamics: a structured model. Theoretical Population Biology 42:35-61.

Hanski, I. 1991. Reply to Nee, Gregory and May. Oikos 62:88-89.

Hanski, I. 1999. Metapopulation ecology. Oxford University Press, Oxford, United Kingdom.

Hanski, I., and M. Gyllenberg. 1993. Two general metapopulation models and the core-satellite species hypothesis. American Naturalist 142:17-41.

Hanski, I., J. Kouki, and A. Halkka. 1993. Three explanations of the positive relationship between distribution and abundance of species. Pages 108-116 in R. E. Ricklefs and D. Schluter, editors. Species diversity in ecological communities: historical and geographical perspectives. University of Chicago Press, Chicago, Illinois, USA.

Harrison, X. A. 2014. Using observation-level random effects to model overdispersion in count data in ecology and evolution. PeerJ 2:e616.

Harvey, P., and M. Pagel. 1991. The comparative method in evolutionary biology. First edition. Oxford University Press, Oxford, United Kingdom.

Heino, J. 2005. Positive relationship between regional distribution and local abundance in stream insects: A consequence of niche breadth or niche position? Ecography 28:345-354.

Heino, J., and J. Soininen. 2006. Regional occupancy in unicellular eukaryotes: A reflection of niche breadth, habitat availability or size-related dispersal capacity? Freshwater Biology 51:672-685.

Holt, A. R., K. J. Gaston, and F. He. 2002. Occupancy-abundance relationships and spatial distribution: A review. Basic and Applied Ecology 3:1-13.
Hutchinson, G. 1957. Population studies-animal ecology and demography - concluding remarks. Cold Spring Harbor Symposia on Quantitative Biology 22:415-427.

Kotze, D. J., J. Niemelä, R. B. O'Hara, and H. Turin. 2003. Testing abundance-range size relationships in European carabid beetles (Coleoptera, Carabidae). Ecography 26: $553-566$.

Lawton, J. H. 1996. Population abundances, geographic ranges and conservation: 1994 Witherby lecture. Bird Study 43:3-19.

Lawton, J. H. 1999. Are there general laws in ecology? Oikos $84: 177-192$

Lefcheck, J. S. 2016. piecewiseSEM: piecewise structural equation modelling in $\mathrm{R}$ for ecology, evolution, and systematics. Methods in Ecology and Evolution 7:573-579.

Marshall, C. T., and K. T. Frank. 1995. Density-dependent habitat selection by juvenile haddock (Melanogrammus aeglefinus) on the southwestern Scotian Shelf. Canadian Journal of Fisheries and Aquatic Sciences 52:1007-1017.

McCreadie, J. W., and P. H. Adler. 2014. Abundance-occupancy relationships of larval black flies (Diptera: Simuliidae) in temperate Nearctic streams. Insect Conservation and Diversity 7:523-532.

Morris, M. G. 1979. Responses of grassland invertebrates to management by cutting. II. Heteroptera. Journal of Applied Ecology 16:417-432.

Nee, S., R. D. Gregory, and R. M. May. 1991. Core and satellite species: theory and artefacts. Oikos 62:83-87.

O'Connor, R. J. 1987. Organization of avian assemblages: the influence of intraspecific habitat dynamics. Pages 163-183 in J. H. R. Gee and P. S. Giller, editors. Organization of communities: past and present. Blackwell Scientific Publications, Oxford, UK.

Oksanen, J., F. G. Blanchet, R. Kindt, P. Legendre, P. R. Minchin, R. B. O'Hara, G. L. Simpson, P. Solymos, M. H. H. Stevens, and H. Wagner. 2015. vegan: community ecology package. R package version 2.2-1. http://CRAN.R-project. org/package=vegan

Östman, Ö. 2010. Abundance-occupancy relationships in metapopulations: examples of rock pool Daphnia. Oecologia 165:687-697.

Päivinen, J., A. Grapputo, V. Kaitala, A. Komonen, J. S. Kotiaho, K. Saarinen, and N. Wahlberg. 2005. Negative density-distribution relationship in butterflies. BMC Biology $3: 5$.

Quinn, R., K. Gaston, T. Blackburn, and B. Eversham. 1997. Abundance-range size relationships of macrolepidoptera in Britain: the effects of taxonomy and life history variables. Ecological Entomology 22:453-461.

R Core Team. 2013. R: a language and environment for statistical computing. R Foundation for Statistical Computing, Vienna, Austria.

Ralph, C. P. 1977. Effect of host plant density on populations of a specialzied, seed-sucking bug, Oncopeltus fasciatus. Ecology 58:799-809.

Rannap, R., A. Lõhmus, and L. Briggs. 2009. Niche position, but not niche breadth, differs in two coexisting amphibians having contrasting trends in Europe. Diversity and Distributions 15:692-700.

Riis, T., and K. Sand-Jensen. 2002. Abundance-range size relationships in stream vegetation in Denmark. Plant Ecology $161: 175-183$

Root, R. B. 1973. Organization of a plant-arthropod association in simple and diverse habitats: the fauna of collards (Brassica oleracea). Ecological Monographs 43:95-124.

Root, R. B., and N. Cappuccino. 1992. Patterns in population change and the organization of the insect community associated with goldenrod. Ecological Monographs 62:393-420. 
Sekar, S. 2012. A meta-analysis of the traits affecting dispersal ability in butterflies: Can wingspan be used as a proxy? Journal of Animal Ecology 81:174-184.

Shipley, B. 2009. Confirmatory path analysis in a generalized multilevel context. Ecology 90:363-368.

Shipley, B. 2013. The AIC model selection method applied to path analytic models compared using a d-separation test. Ecology 94:560-564.

Siemann, E., D. Tilman, and J. Haarstad. 1999. Abundance, diversity and body size: patterns from a grassland arthropod community. Journal of Animal Ecology 68:824-835.

Simons, N. K., M. M. Gossner, T. M. Lewinsohn, M. Lange, M. Türke, and W. W. Weisser. 2015. Effects of land-use intensity on arthropod species abundance distributions in grasslands. Journal of Animal Ecology 84:143-154.

Simons, N. K., et al. 2014. Resource-mediated indirect effects of grassland management on arthropod diversity. PLoS ONE 9:e107033.

Sinnott, R. W. 1984. Virtues of the haversine. Sky and Telescope 68:158-159.

Socher, S. A., D. Prati, S. Boch, J. Müller, V. H. Klaus, N. Hölzel, and M. Fischer. 2012. Direct and productivity-mediated indirect effects of fertilization, mowing and grazing on grassland species richness. Journal of Ecology 100:1391-1399.

Socher, S. A., et al. 2013. Interacting effects of fertilization, mowing and grazing on plant species diversity of 1500 grasslands in Germany differ between regions. Basic and Applied Ecology 14:126-136.

Tales, E., P. Keith, and T. Oberdorff. 2004. Density-range size relationships in French riverine fishes. Oecologia 138:360-370.

Tonkin, J. D., F. O. Arimoro, and P. Haase. 2016. Exploring stream communities in a tropical biodiversity hotspot: biodiversity, regional occupancy, niche characteristics and environmental correlates. Biodiversity and Conservation 25:975-993.

Venier, L. A., and L. Fahrig. 1996. Habitat availability causes the species abundance-distribution relationship. Oikos 76 : 564-570.

Venier, L. A., and L. Fahrig. 1998. Intra-specific abundancedistribution relationships. Oikos 82:483-490.

Verberk, W. C. E. P., G. Van Der Velde, and H. Esselink. 2010. Explaining abundance-occupancy relationships in specialists and generalists: a case study on aquatic macroinvertebrates in standing waters. Journal of Animal Ecology 79:589-601.

Wiens, J. A., J. T. Rotenberry, and B. Van Horne. 1987. Habitat occupancy patterns of North American shrubsteppe birds: the effects of spatial scale. Oikos 48:132-147.

Wisskirchen, R., and H. Haeupler. 1998. Standardliste der Farn-und Blütenpflanzen Deutschlands. Verlag Eugen Ulmer, Stuttgart, Germany.

Zuur, A. F., E. N. Ieno, and C. S. Elphick. 2010. A protocol for data exploration to avoid common statistical problems. Methods in Ecology and Evolution 1:3-14.

\section{SUPPORTING INFORMATION}

Additional supporting information may be found in the online version of this article at http://onlinelibrary.wiley.com/doi/ 10.1002/ecy.1947/suppinfo 